\title{
Experiment Study for the Treatment of Pharmaceutical Comprehensive
}

\author{
Wastewater \\ Shiyue Liu ${ }^{1}$, Qin Liu ${ }^{1}$, Heli Wang ${ }^{1 *}$, Yunping $\mathrm{Li}^{1}$, Yilin Han ${ }^{1}$, \\ ${ }^{1}$ China University of Geosciences (Beijing), Beijing, 100083, China \\ aemail: 1083789419@qq.com, bemail:liuqin410@hotmail.com, cemail:wangheli@cugb.edu.cn, \\ demail:qiuzhilyp@163.com, eemail: hanyilin95@163.com
}

Keywords: Comprehensive wastewater, hydrolytic acidification, pilot scale experiment

Abstract. Combined the actual monitoring results of wastewater of Northeast Pharmaceutical Group, "grill + grit + primary sedimentation (grease) + regulation pool + hydrolytic acidification + contact oxidation + secondary sedimentation" was proposed to applied in the process. The treatment effects of natural sedimentation and coagulation sedimentation on wastewater were discussed after the experiment and pilot test. The influence of COD concentration, hydraulic residence time (HRT), temperature and other effects on the hydrolysis acidification process and improving of $\mathrm{B} / \mathrm{C}$ ratio were analyzed. In addition, the treatment effects of influent COD concentration, HRT and temperature on the contact oxidation process were explored. The results show that the wastewater can be stabilized to meet emission standards after the process in this study.

\section{Introduction}

Northeast Pharmaceutical Group Co., Ltd. is a comprehensive pharmaceutical enterprise group in China, with two production of plate and raw material production plate currently. (Pcoside, chloramphenicol, berberine, etc.), and chemical products (piracetam and other cerebrovascular drugs, propyne (Vc, L-carnitine, etc.), antibiotics products (fosfomycin, chloramphenicol, berberine, etc.) Alcohols, etc.). The preparation of plate products are divided into non-sterile preparations and sterile formulations. Non-sterile preparations include tablets, oral solutions, pills, suppositories, capsules, powders and new products, sterile preparations mainly include fosfomycin sodium powder, Anselon powder, cefotaxime sodium, ceftazidime powder and so on. Therefore, the waste water production of Northeast Pharmaceutical Group has complex composition, toxic and hazardous substances content and low biodegradability,which is a typical integrated mixed production wastewater [1]. Because of the antibacterial effect of the medicinal active ingredient of the waste water, biochemical treatment becomes very difficult.

The characteristics of industrial production pharmaceutical wastewater are shown in Table 1 [2]. 
Table 1 The characteristics of industrial production pharmaceutical wastewater

\begin{tabular}{|c|c|}
\hline Source of waste water & Characteristics of water quality \\
\hline $\begin{array}{c}\text { Purified water, water for injection } \\
\text { equipment }\end{array}$ & Acid and alkali wastewater \\
\hline $\begin{array}{l}\text { Packaging containers cleaning } \\
\text { wastewater }\end{array}$ & $\begin{array}{l}\text { Low concentration of pollutant, large water amount, COD }<100 \\
\qquad \mathrm{mg} / \mathrm{L}, \mathrm{SS}<50 \mathrm{mg} / \mathrm{L}\end{array}$ \\
\hline Process equipment cleaning wastewater & $\begin{array}{l}\text { Containing active ingredients, inhibitory to microorganisms, small } \\
\text { water amount, COD }<1500 \mathrm{mg} / \mathrm{L}\end{array}$ \\
\hline Ground cleaning wastewater & Low concentration of pollutants, COD $<400 \mathrm{mg} / \mathrm{L}$ \\
\hline Domestic sewage & Easy to degrade, $C O D \leq 300 \mathrm{mg} / \mathrm{L}$ \\
\hline
\end{tabular}

The comprehensive pharmaceutical wastewater consists of the pretreated industrial production pharmaceutical wastewater. At present, the technologies used for the comprehesive pharmaceutical industry mainly includes biological treatment, such as activated sludge process, biosolytic acidification, contact oxidationetc.; Physical and chemical treatment, such as air flotation, filtration, flocculation sedimentation, disinfection and other physical and chemical methods [3-7]. But these processes still have a certain gap to achieve the first-class emission standards of the "Integrated Wastewater Discharge Standard" (GB8978-1996).

This study took the wastewater of the Northeast pharmaceutical plant as the target, starting from the discussion of comprehensive wastewater treatment technology achievements and engineering examples. This study identified the biological treatment technology as the core of the preparation of wastewater treatment process technology [8-11]. The results can be used to guide the wastewater treatment of other pharmaceutical enterprises in the northeastern region, and contribute to the wastewater treatment project construction of these enterprises.

\section{Materials and methods}

Wastewater quality. The sample was collected from the Northeast Pharmaceutical Group comprehensive water plant production process, and the results of wastewater quality was shown in Table 2.

Table 2 The quality of comprehensive pharmaceutical wastewater

\begin{tabular}{cc}
\hline Category & Concentration/ $(\mathrm{mg} / \mathrm{L})$ \\
\hline $\mathrm{PH}$ & 5.6 \\
$\mathrm{COD}$ & $230 \sim 790$ \\
$\mathrm{BOD}_{5}$ & $140 \sim 380$ \\
$\mathrm{NP}$ & 1 \\
$\mathrm{NH}_{4}{ }^{+}-\mathrm{N}$ & 25 \\
Inorganic salts & 750 \\
Petroleum hydrocarbons & 15 \\
$\mathrm{SS}$ & 40
\end{tabular}

It was shown that the wastewater COD concentration is not too high, but $\mathrm{BOD}_{5} / \mathrm{COD}_{\mathrm{Cr}}$ value is low, it is not suitable for biochemical treatment. Therefore, it is necessary to make a pretreatment. 
Process Flow. Aaccording to the previous research results, waste water and water quality characteristics, emission standards, reuse requirements, economic indicators and other factors, it is appropriate to utilize the process of hydrolytic acidification - aerobic contact oxidation proess [12-14] The sludge were sampled from Northeast Pharmaceutical Group Co., Ltd. sewage treatment center was inoculated into device. The basic process was shown in Figure 1.

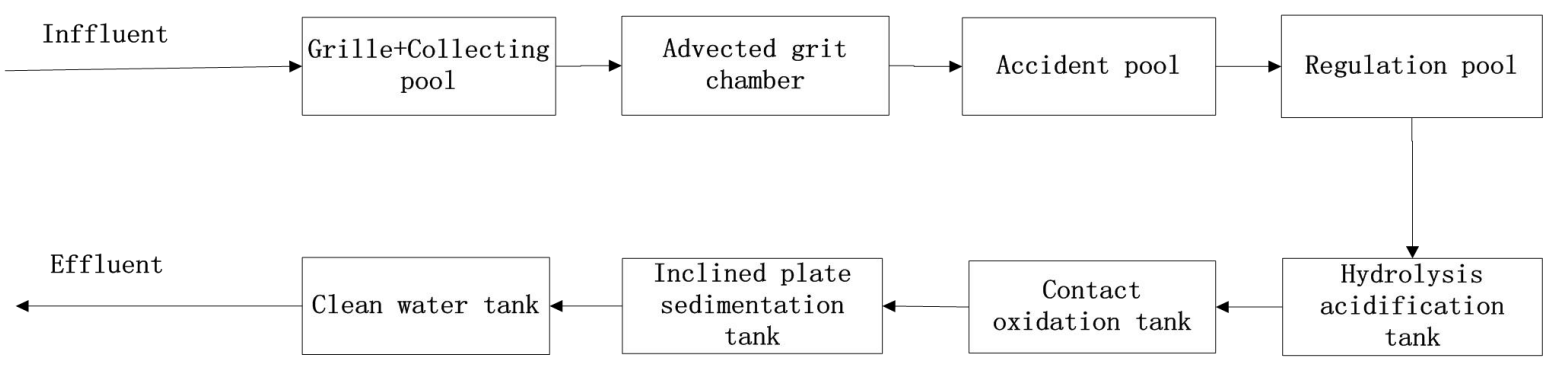

Figure 1 The basic process

Operation process. The experiment was carried out on the pilot scale of the mixed preparation pharmaceutical wastewater treatment facilities. The influent was the actual mixed preparation pharmaceutical wastewater. Wastewater past through the grille, grit chamber, the first precipitation (oil), regulating pool, hydrolytic acidification pool, contact oxidation tank, and was discharge after the second precipitation. The operating conditions of the pretreatment tank, the hydrolysis acidification tank and the contact oxidation tank were changed to examine the operation effect of the system.

Analytical methods. Water samples were analyzed by using the standard method [15] during the test. COD and ammonia content were measured by spectrophotometry (UNIC4802, Unique, USA) and SS was measured by weight method. The $\mathrm{pH}$ was measured using an OHAUS Starter 3C type $\mathrm{pH}$ meter. The removal rate of $\mathrm{COD}_{\mathrm{Cr}}$ was calculated as follows.

$$
\eta=\left(1-\frac{C_{t}}{C_{0}}\right) \times 100 \%
$$

$\mathrm{C}_{0}-$ Initial concentration of $\mathrm{COD}_{\mathrm{Cr}}$ in wastewater, $\mathrm{mg} / \mathrm{L}$;

$\mathrm{Ct}-\mathrm{t}$ moment concentration of $\mathrm{COD}_{\mathrm{Cr}}$ in wastewater, $\mathrm{mg} / \mathrm{L}$ 。

\section{Results and discussion}

Pollutant Removal Effect of Free Precipitation. Observed the gravity sedimentation effect (no dosing) of small sedimentation tank before being tested, the results were shown in Table 3.

Table 3 the removal effect of waste water SS by gravity sedimentation process

\begin{tabular}{ccc}
\hline Settling time $/ \mathrm{h}$ & SS concentration after precipitation $/(\mathrm{mg} / \mathrm{L})$ & Removal rate $/ \%$ \\
\hline 0 & 42 & - \\
0.5 & 37 & 11 \\
2.0 & 35 & 17 \\
4.0 & 33 & 21
\end{tabular}

The results showed that the removal rate of SS can reach $21 \%$ after 4 h gravity sedimentation without adding any flocculant. Compared with $2 \mathrm{~h}$, the effect is not significant. In addition, it is not significant to increase the gravity settling time, while the cost of construction will be a substantial increase in the case of the total amount of suspended solids in a low level. Therefore, it is not 
recommended to take long gravity residence time.

Pollutant Removal Effect of Flocculation and Sedimentation. In the flocculation test, the water sample was allowed to stand $0.5 \mathrm{~h}$, after dosing polyaluminium chloride and polyacrylamide, the optimal dosage of the medicament is PAC $45 \mathrm{mg} / \mathrm{L}$, PAM $0.2 \mathrm{mg}$ / L. The results are shown in Table 4.

Table 4 Removal effect of flocculation and sedimentation on SS and COD of wastewater

\begin{tabular}{cccc}
\hline Project & Raw water & After flocculation & Removal rate $/ \%$ \\
\hline SS & 40 & 12 & 70 \\
COD & 439 & 425 & - \\
\hline
\end{tabular}

The experimental data showed that flocculant dosing can indeed improve the settlement effect, but COD does not decrease with SS after the wastewater is stationary. The results indicated that the composition of SS is mainly inorganic matter. It is unnecessary to reduce the content of SS by adding drugs.

The effect of pharmaceutical wastewater treatment system. The pilot device running effect was gradually stabilized, with the warming of weather, so the operational data in this cycle period was choosen for analyzing (shown in Figure 2, Figure 3).

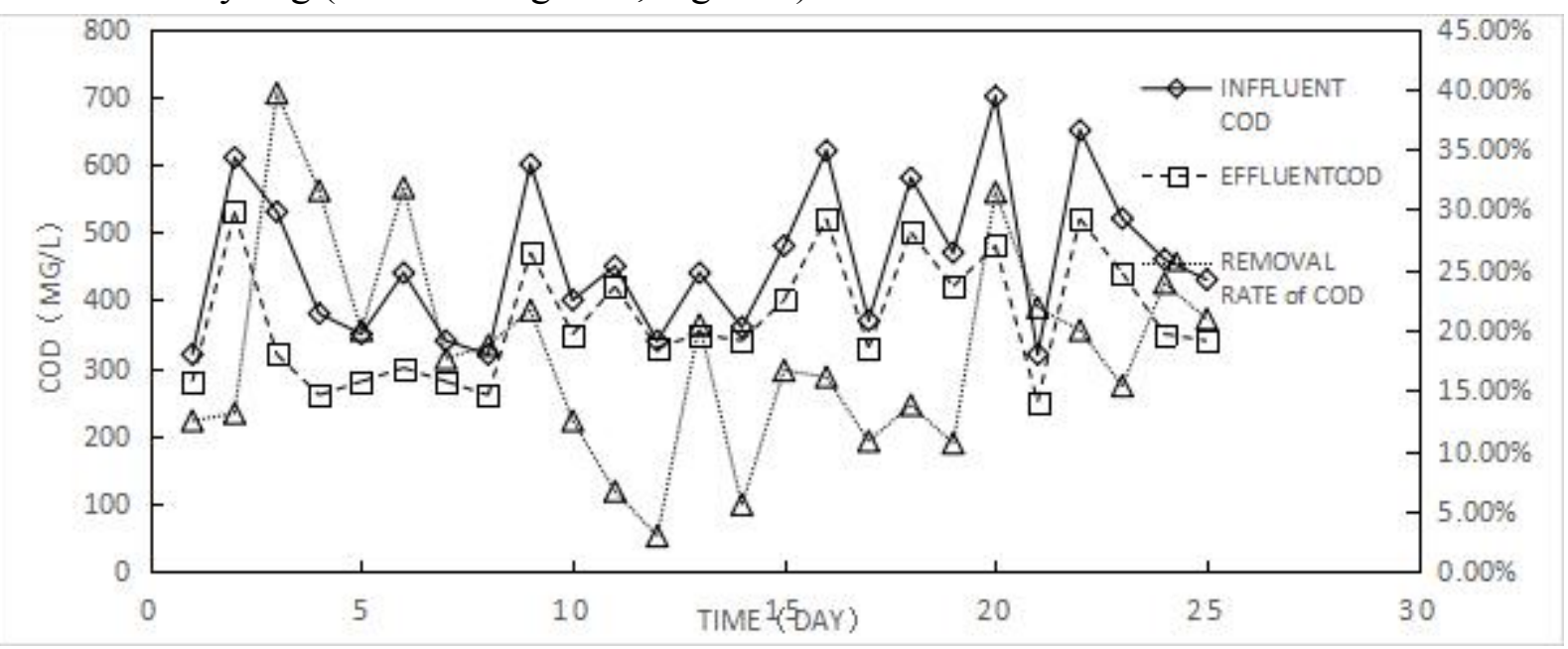

Figure 2 Removal effect of hydrolysis acidification process on COD in wastewater

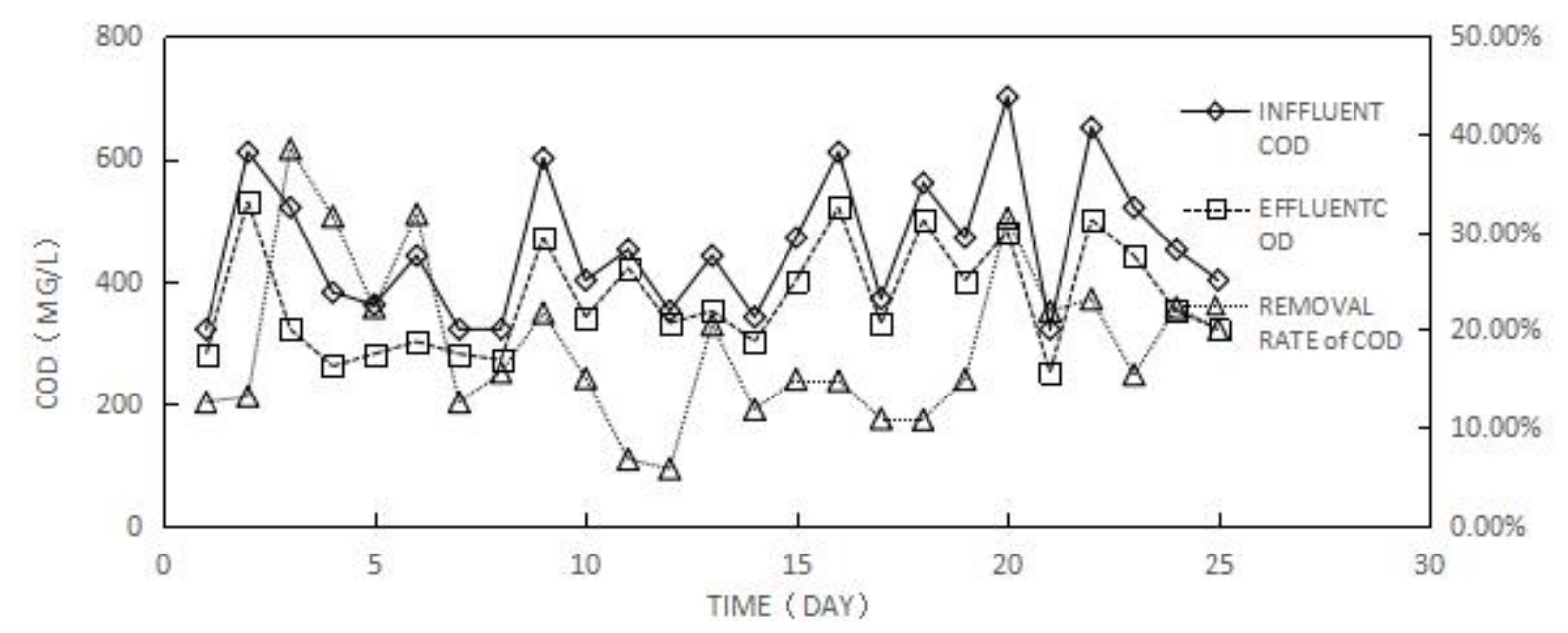

Figure 3 Removal effect of contact oxidation process on COD in wastewater

The average of COD removal rate was $18 \%$ in the hydrolysis and acidification stage. Although 
the results were not satisfactory, effluent COD concentration tended to be more stable than raw water. In addition, it is neccessary to consider the influence of the hydrolytic acidification on B / C value enhancement and engineering operation.

In addition, the average volume load of COD in contact oxidation tank is $0.62 \mathrm{~kg} /\left(\mathrm{m}^{3} \cdot \mathrm{d}\right)$, the settling performance of activated sludge is good, effluent COD average concentration is $55 \mathrm{mg} / \mathrm{L}$, ciliates and other protozoaon can be clearly seen in microscopic under this condition. Through the observation of the overall operational data, the effluent concentration did not fluctuate with the influent. It is indicated that test device have a removal impact on preparation wastewater and have a certain impact resistance.

\section{Conclusion}

In view of the water quality characteristics and engineering demand of the pharmaceutical mixed pharmaceutical production wastewater, the "precipitation - hydrolytic acidification - contact oxidation" combination process was designed, a pilot plant with a pilot scale was set up and a pilot study was conducted to obtain the following conclusions.

(1) Under the condition of no flocculant, the removal rate of SS was $21 \%$ after $2 \mathrm{~h}$ gravity treatment of mixed wastewater. The removal rate of SS was up to $70 \%$ after $0.5 \mathrm{~h}$ adding poly aluminum chloride (45 mg / L) and polyacrylamide $(0.2 \mathrm{mg} / \mathrm{L})$, but the COD removal effect is limited.

(2) After pretreating, wastewater enters the hydrolysis and acidification and contact oxidation treatment unit, COD removal rate of wastewater was about $18 \%$, but the biodegradation of wastewater was obvious, the removal rate of COD was about $70 \%$, the average concentration of COD was $55 \mathrm{mg} / \mathrm{L}$.

(3) The removal rate of COD reached $80 \%$ by using "precipitation-hydrolytic acidification-contact oxidation" process, the effluent could achieve the discharge standards of wastewater stably. Therefore this process has a good prospect of engineering application.

\section{Acknowledgments}

This work was financially supported by the "research and demonstration of ecological low-energy-consuming treatment technology and key equipment for processing rural domestic pollution from water resource region".

\section{References}

[1] FAN Juhong, LIU Rui, YU Sulin, et al.Study on the Effect of Substances Pretreatment Strengthened Pharmaceutical Wastewater Treatment [J]. China Water Supply and Drainage 2012,28 (23): 34-37.

[2] Ministry of Environmental Protection. Pharmaceutical industry (chemical synthesis, fermentation and preparation) pollution control the best feasible technical guidelines [M], Beijing: China Environmental Science Press, 2013.

[3] Zhang Shuping. Coagulation - Anaerobic digestion of pharmaceutical wastewater treatment [D]. Chengdu: Southwest Jiaotong University, 2010.

[4] Song Xin, Ren Liren, Wu Dan, et al. Research status and progress of advanced treatment technology of pharmaceutical wastewater [J] Guangzhou Chemical Industry, 2012, 40 (12): 29-31.

[5] NG K K, SHI X Q, ONG S L, et al. Pyrosequencing published microbial community profile in anaerobic bio-entrapped membrane reactor for pharmaceutical wastewater treatment [J]. 
Bioresource Technology, 2016, 200: 1076-1079.

[6] Zhou Lili. Chemical synthesis of pharmaceutical wastewater efficient anaerobic biological treatment technology research [D], Tianjin: Tianjin University, 2010.

[7] Xu Yanchun, Yan Zipeng, Yan Yongjiang, etc. Hydrolysis acidification -SBR process for solid preparation and chemical synthesis of pharmaceutical wastewater $[\mathrm{J}]$, water supply and drainage, 2011, 37 (10): 68-70.

[8] Pan Zhiyan, Chen Zhaixia, Wang Quanyuan, etc. Pharmaceutical industry water pollution prevention and control technology research progress [J], water treatment technology, 2004, 28 (02): 68-71.

[9] LOU Juqing. Progress of Pharmaceutical Wastewater Treatment [J], Journal of Chongqing University of Science and Technology (Natural Science Edition), 2006,8 (04): 13-15.

[10] Ma Wenxin, Chen Weizhong, Ren Jianjun, et al. Pharmaceutical wastewater pretreatment technology exploration [J], environmental pollution and prevention, 2001,23 (02): 87-89.

[11] Luo Nan, Peng Bo. SBR treatment of chemical preparation wastewater [J]. Environmental Pollution and Control, 1990, 2 (21): 20-22.

[12] Wu Guohu, Li Peng, Wang Shuguang, etc. Coagulation treatment of pharmaceutical wastewater treatment [J]. Water treatment technology, 2000, 26 (01): 53-55.

[13] Pan Zhiqiang. Oxytetracycline, oxytetracycline wastewater chemical flotation treatment [J], industrial water treatment, 1991, 11 (01): 24-26.

[14] Zeng Lixuan, Peng Ying, Zhang Qiuyun. Experimental Study on Wastewater Treatment of Enzyme [J], Environmental Pollution Control Technology and Equipment, 2002, 3 (09), 24-27.

[15] State Environmental Protection Administration. Water and Wastewater Monitoring and Analysis Methods (4th ed.) [M]. Beijing: China Environmental Science Press, 2002. 